\title{
Comparison of the effects of differentially sulphated bovine kidney- and porcine intestine-derived heparan sulphate on breast carcinoma cellular behaviour
}

\author{
CHUN-HUA GUO ${ }^{1}$, CHUAY-YENG KOO ${ }^{1}$, BOON-HUAT BAY ${ }^{1}$, PUAY-HOON TAN ${ }^{2}$ and GEORGE W. YIP ${ }^{1}$ \\ ${ }^{1}$ Department of Anatomy, Yong Loo Lin School of Medicine, National University of Singapore, \\ 4 Medical Drive, Block MD 10, Singapore 117597; ${ }^{2}$ Department of Pathology, \\ Singapore General Hospital, Outram Road, Singapore 169608, Singapore
}

Received July 12, 2007; Accepted September 3, 2007

\begin{abstract}
Heparan sulphate is a sulphated glycosaminoglycan and is able to bind to and regulate the activity of many growth and signalling factors. We have previously shown that its expression is correlated with tumour grade and cell proliferation in breast phyllodes tumours. In this study, we examined the use of heparan sulphate as a biomarker of invasive ductal carcinoma and the effects of differentially sulphated heparan species on breast cancer cell behaviour. Immunohistochemistry using the 10E4 monoclonal antibody was carried out on 32 paraffin-embedded breast cancer specimens and paired non-cancerous breast tissues to compare the expression patterns of heparan sulphate. Upregulated expression of the sulphated 10E4 epitope in heparan sulphate was detected in both epithelial and stromal compartments of breast cancer compared with normal mammary tissues, with a $2.8 \mathrm{X}$ increase in immunoreactivity score. To determine the effects of differentially sulphated heparan sulphate molecules on breast cancer behaviour, cultured breast carcinoma cells were treated with chlorate, a competitive inhibitor of glycosaminoglycan sulphation, and two different heparan sulphate species. Inhibition of glycosaminoglycan sulphation resulted in a significant increase in cancer cell adhesion and a reduction in cell migration, together with upregulated expression of focal adhesion kinase and paxillin. Both porcine intestineand bovine kidney-derived heparan sulphate species could block the change in cell adhesion. However, the former heparan sulphate species completely abolished, while the
\end{abstract}

Correspondence to: Dr George W. Yip, Department of Anatomy, Yong Loo Lin School of Medicine, National University of Singapore, 4 Medical Drive, Block MD 10, Singapore 117597, Singapore

E-mail: georgeyip@nus.edu.sg

Key words: breast cancer, heparan sulphate, differential sulphation, bovine kidney, porcine intestine, cell adhesion, cell migration latter exacerbated, the chlorate-induced decrease in cell migration. The results show that heparan sulphate is a useful biomarker of breast invasive ductal carcinoma. Different sulphation patterns of heparan sulphate residues have differential effects in regulating breast cancer cellular behaviour, and this may be exploited to develop heparan sulphate into a useful target for treatment of breast carcinoma.

\section{Introduction}

Breast carcinoma is the most widespread form of malignancy in women worldwide, and the commonest cause of cancerrelated deaths $(1,2)$. Besides clinical and histopathological staging and hormonal receptor status, cancer cell adhesion and migration are important parameters that affect patient prognosis $(3,4)$. Thus, understanding the molecular regulators of cancer cellular behaviour and determination of their effects on tumour cell adhesion and migration are essential to a better comprehension of cancer biology, and is of fundamental importance in the development of therapeutic targets.

Heparan sulphate is an unbranched, polyanionic glycosaminoglycan composed of alternating repeats of glucosamine and glucuronic/iduronic acid residues $(5,6)$. Heparan sulphate chains are attached to core protein backbones to form heparan sulphate proteoglycans, which can be found attached to the cell surface or within the extracellular matrix (7). The physiological function of heparan sulphate is highly dependent on the presence of sulphate groups, which modulate the ability of heparan sulphate to bind to and interact with different growth and signalling factors (7-9). The importance of differential sulphation of heparan sulphate has been highlighted by recent studies on knockout mice, in which loss of heparan 2-O-sulphation resulted in renal, ocular and skeletal defects whereas absence of $\mathrm{N}$-sulphation led to pulmonary hypoplasia and respiratory distress in newborn pups (10-12).

Studies on the core proteins of heparan sulphate proteoglycans using breast cancer tissue samples have shown that these molecules may be important prognostic indicators. Several authors have reported increased expression of the core protein of syndecan-1, a transmembrane heparan 
sulphate proteoglycan, in women with aggressive forms of breast cancer associated with a poorer prognosis (13-15). Indeed, expression of syndecan-1 in breast ductal carcinoma in situ was found to be associated with the presence of angiogenic and lymphangiogenic factors, and correlated with the response of primary breast cancer to neoadjuvant chemotherapy $(16,17)$. Upregulated expression of the core protein of glypican-1, a glycosylphosphatidylinositol-linked heparan sulphate proteoglycan, was also noted in human breast cancer and influenced the response of cancer cells to growth factors (18).

In contrast to the heparan sulphate proteoglycan core proteins, relatively less is known about the potential use of the heparan sulphate glycosaminoglycan chain as a biomarker of invasive ductal carcinoma in clinical samples, and the effects of differentially sulphated heparan sulphate species on breast cancer cellular behaviour. We have recently shown that expression of the heparan sulphate glycosaminoglycan chain is correlated with tumour grade and cell proliferation in phyllodes tumours (19). In the current study, we present evidence that sulphated heparan is upregulated in human breast invasive carcinoma tissues, and that the level of sulphation influences tumour cellular behaviour. We also show that differentially sulphated porcine intestineand bovine kidney-derived heparan sulphate species have dissimilar effects on breast carcinoma cells.

\section{Materials and methods}

Clinical samples. A total of 32 archived, formalin-fixed paraffin-embedded breast cancer specimens and paired noncancerous breast tissues from the corresponding patients were obtained from the Department of Pathology, Singapore General Hospital for this study. Ethics approval was obtained from the Institutional Review Board, Singapore General Hospital.

Immunohistochemistry. Immunohistochemical staining of clinical samples using the 10E4 antibody was performed as previously described (19). Briefly, 4- $\mu \mathrm{m}$ thick tissue sections were deparaffinised and rehydrated. Antigen retrieval using $0.1 \mathrm{mg} / \mathrm{ml}$ testicular hyaluronidase (Sigma-Aldrich, St. Louis, MO) in PBS was carried out at room temperature for $2 \mathrm{~h}$ prior to overnight incubation with the $10 \mathrm{E} 4$ primary antibody (Seikagaku, Tokyo, Japan) at $4^{\circ} \mathrm{C}$. After washing, colorimetric detection was achieved using the avidin-biotincomplex technique and diaminobenzidine. The sections were examined using an Olympus BX51 microscope and analysed using the Image J v1.33 software (NIH, USA). An immunoreactivity score (IRS) was determined for each specimen, calculated by multiplying the percentage of cells stained by the staining intensity.

Cell culture. MCF-7 and MDA-MB-231 human breast cancer cell lines were obtained from the American Tissue Culture Collection (Manassas, VA). Cells were cultured in Dulbecco's modified Eagle's medium (DMEM) supplemented with 7.5\% foetal bovine serum (FBS), $2 \mathrm{mM}$ glutamine and $40 \mathrm{mg} / \mathrm{l}$ gentamycin in a humidified $5 \% \mathrm{CO}_{2}$ incubator at $37^{\circ} \mathrm{C}$. Bovine kidney-and porcine intestine-derived heparan sulphate species, chlorate, and sulphate (all from Sigma-Aldrich) were added in various combinations to the culture medium.

Quantification of sulphated glycosaminoglycans. Cultured cells were collected with a cell scraper, and the glycosaminoglycans extracted by ethanol precipitation as previously described (20). Quantification of sulphated glycosaminoglycans was carried out using the Blyscan assay (Biocolor, Newtownabbey, Northern Ireland), a dye-binding assay that measures sulphated glycosaminoglycans without interference from non-sulphated glycosaminoglycans, according to the manufacturer's protocol. Briefly, the extracted glycosaminoglycans were allowed to bind to the Blyscan dye reagent to form a precipitate, which was then pelleted by centrifugation at 9,000 x g for $10 \mathrm{~min}$. The precipitate was dissolved in the dissociation reagent, and the absorbance at $656 \mathrm{~nm}$ measured using a spectrophotometer.

Cell adhesion assay. Coating of 96-well culture plates with $20 \mu \mathrm{g} / \mathrm{ml}$ fibronectin (BD Biosciences, San Jose, CA) in phosphate-buffered saline (PBS) was carried out overnight at $4^{\circ} \mathrm{C}$ (21). The wells were washed with PBS and the unbound sites blocked using $1 \%$ bovine serum albumin for $1 \mathrm{~h}$ at room temperature. The wells were then washed with PBS and dried.

Cells were pre-cultured for $48 \mathrm{~h}$ in serum-containing DMEM supplemented with PBS (control group), $30 \mathrm{mM}$ chlorate or $30 \mathrm{mM}$ chlorate plus $100 \mathrm{ng} / \mathrm{ml}$ heparan sulphate. The cells were then collected and seeded at a density of $1 \times 10^{5}$ cells per well in the above fibronectin-coated culture plates and allowed to attach for $30 \mathrm{~min}$ at $37^{\circ} \mathrm{C}$. The attached cells were washed with PBS, fixed for $15 \mathrm{~min}$ in $4 \%$ paraformaldehyde, and stained for $30 \mathrm{~min}$ using $0.25 \%$ crystal violet in $20 \%$ methanol. After washing, the number of attached cells was determined by releasing the crystal violet with $1 \%$ sodium dodecyl sulphate and measuring the absorbance at $595 \mathrm{~nm}$.

Cell migration assay. Cancer cells were cultured in serumcontaining DMEM in 6-well plates until they reached $90 \%$ confluence. A horizontal line was then scraped across the bottom of each well using a sterile $100-\mu 1$ plastic pipette tip, after which the culture was continued and the culture medium was supplemented with PBS (control group), $30 \mathrm{mM}$ chlorate or $30 \mathrm{mM}$ chlorate plus $100 \mathrm{ng} / \mathrm{ml}$ heparan sulphate. The average distance between the wound edges in each well was determined by measurement at five randomly selected sites along the length of the wound. The difference in the wound gap distance at 0 and $18 \mathrm{~h}$ after scraping was calculated to determine the distance migrated.

Cell proliferation assay. Cells were seeded in 96-well plates at a density of $4 \times 10^{3}$ cells per well and cultured for $72 \mathrm{~h}$ in serum-containing DMEM supplemented with PBS (control group), $30 \mathrm{mM}$ chlorate or $30 \mathrm{mM}$ chlorate plus $100 \mathrm{ng} / \mathrm{ml}$ heparan sulphate. At the end of the culture period, the cells were washed with PBS, fixed in $4 \%$ paraformaldehyde for $15 \mathrm{~min}$, and stained using $0.25 \%$ crystal violet in $20 \%$ methanol for $30 \mathrm{~min}$. After washing, 1\% sodium dodecyl sulphate was added for $1 \mathrm{~h}$ to release the crystal violet, and 
Table I. Intron-spanning primers used in real-time RT-PCR analysis.

\begin{tabular}{|c|c|c|c|}
\hline Gene & RefSeq No. & Primer sequence & Product (bp) \\
\hline \multirow[t]{2}{*}{ ITGB1 } & NM_002211 & Forward: 5'-CTGCGAGTGTGGTGTCTGTAA-3' & 162 \\
\hline & & Reverse: 5'-GAACATTCCTGTGTGCATGTG-3' & \\
\hline \multirow[t]{2}{*}{$F A K$} & NM_005607 & Forward: 5'-TGGACGATGTATTGGAGAAGG-3' & 175 \\
\hline & & Reverse: 5'-ATGAGGATGGTCAAACTGACG-3' & \\
\hline \multirow[t]{2}{*}{$P X N$} & NM_002859 & Forward: 5'-CCACACATACCAGGAGATTGC-3' & 189 \\
\hline & & Reverse: 5'-GGGTTGGAGACACTGGAAGTT-3' & \\
\hline \multirow[t]{2}{*}{$R P L P O$} & NM_001002 & Forward: 5'-CTGTTGCATCAGTACCCCATT-3' & 103 \\
\hline & & Reverse: 5'-GCCTTGACCTTTTCAGCAAG-3' & \\
\hline
\end{tabular}

the absorbance was then measured at $595 \mathrm{~nm}$ using a microplate reader.

Fluorescence immunocytochemistry. Cover slips were coated with fibronectin as described above. Cells were pre-cultured for $48 \mathrm{~h}$ in serum-containing DMEM supplemented with PBS (control group) or $30 \mathrm{mM}$ chlorate. The cells were then trypsinised and washed in PBS. They were seeded at a density of $1 \times 10^{5}$ cells per coverslip and allowed to attach for $2 \mathrm{~h}$ to form adhesion. Unattached cells were then washed off. Attached cells were fixed in $4 \%$ paraformaldehyde for 10 min and washed with PBS containing 0.2\% Triton X-100. After blocking, the cells were incubated with a 1:100 dilution of either mouse anti-paxillin $\mathrm{IgG}_{1}$ antibody, clone 165 (BD Biosciences) or rabbit anti-FAK antibody (Santa Cruz Biotechnology, Santa Cruz, CA) at $4^{\circ} \mathrm{C}$ overnight as previously described $(22,23)$. After washing, the signal was detected using an Alexa Fluor 568 goat anti-mouse secondary antibody (Invitrogen, Carlsbad, CA) or an Alexa Fluor 568 goat anti-rabbit secondary antibody respectively. To achieve double fluorescence labelling for F-actin, the cells were then incubated with Alexa Fluor 488 phalloidin (1:50 dilution) for $1 \mathrm{~h}$ at room temperature. The samples were examined using a FluoView FV1000 laser scanning confocal microscope (Olympus, Melville, NY).

For immunocytochemical detection of heparan sulphate, cells were fixed using Sainte-Marie's fixative as this gives better preservation of glycosaminoglycans (24). After blocking, cells were incubated with the anti-heparan sulphate antibody 10E4 at 1:100 dilution followed by an Alexa Fluor 488 goat anti-mouse IgM secondary antibody.

Real-time RT-PCR. Total RNA was extracted from cultured cells using the RNeasy Mini Kit (Qiagen, Valencia, CA) according to the manufacturer's protocol. After synthesis of cDNA using Superscript III (Invitrogen) and random hexamers, real-time PCR was carried out in a LightCycler (Roche, Indianapolis, IN) with the intron-spanning primers listed in Table I. After an initial activation step of $95^{\circ} \mathrm{C}$ for $15 \mathrm{~min}, 45 \mathrm{PCR}$ cycles were performed as previously described: denaturation step of $94^{\circ} \mathrm{C}$ for $15 \mathrm{sec}$, annealing step of $60^{\circ} \mathrm{C}$ for $25 \mathrm{sec}$, and extension step of $72^{\circ} \mathrm{C}$ for $18 \mathrm{sec}$ (25). Melting curve analysis was carried out to verify the specificity of the amplification, and the size of the PCR product was confirmed by electrophoresis on a $2 \%$ agarose gel. The $2^{-\Delta \Delta \mathrm{Ct}}$ method was used to determine the relative level of expression of gene transcripts after normalisation to RPLPO (also known as 36B4), an oestradiol-independent mRNA control (26).

Western blot analysis. Cancer cells were grown in 100-mm petri dishes for $48 \mathrm{~h}$ and then lysed with $200 \mu \mathrm{l}$ cold lysis buffer consisting of $50 \mathrm{mM}$ HEPES, $150 \mathrm{mM}$ sodium chloride, $1 \%$ Triton $\mathrm{X}-100,5 \mu \mathrm{g} / \mathrm{ml}$ pepstatin A, $5 \mu \mathrm{g} / \mathrm{ml}$ leupeptin, $2 \mu \mathrm{g} / \mathrm{ml}$ aprotinin, $1 \mathrm{mM}$ phenylmethylsulphonyl fluoride, $100 \mathrm{mM}$ sodium fluoride and $1 \mathrm{mM}$ sodium vanadate, $\mathrm{pH}$ 7.5. After standing for $20 \mathrm{~min}$ on ice, the protein supernatant was collected by centrifugation at 13,000 x g for $20 \mathrm{~min}$. Twenty micrograms of protein were analysed by Western blotting with the ECL kit (Amersham, Little Chalfont, UK) using the following antibodies to probe the Western membrane after stripping: mouse anti-paxillin $\mathrm{IgG}_{1}$ antibody clone 165 , mouse anti-FAK $\operatorname{IgG}_{1}$ antibody clone 77 , and mouse anti-ß1-integrin $\mathrm{IgG}_{1}$ antibody clone 18 (all from BD Biosciences). The relative protein expression level was determined by densitometry measurement of the band intensity and normalisation to $\beta$-actin.

Statistical analysis. All experiments consisted of at least three replicates. Statistical comparison between two groups was performed by the Student's t-test, and among three groups by one-way analysis of variance (ANOVA) with Tukey's post test using GraphPad Prism v4.03 for Windows (GraphPad Software, San Diego, CA). The Wilcoxon matched pairs test was used for comparison of clinical samples. Statistical significance was defined as a p-value of $<0.05$.

\section{Results}

Expression of heparan sulphate in breast cancer tissues. To determine if heparan sulphate is differentially expressed between breast carcinoma and non-cancerous breast tissues, we examined the expression of the 10E4 epitope in both epithelial and stromal compartments of 32 samples of invasive ductal carcinoma and paired non-cancerous mammary tissues from the corresponding patients. The mouse monoclonal antibody 10E4 is a well-established anti-heparan sulphate antibody, and requires the presence 
A

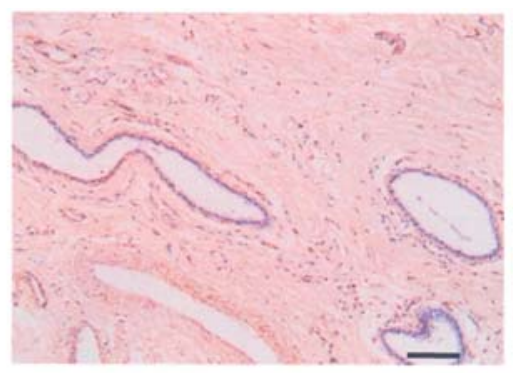

C

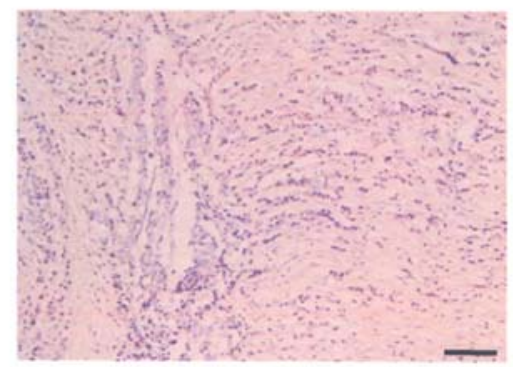

E

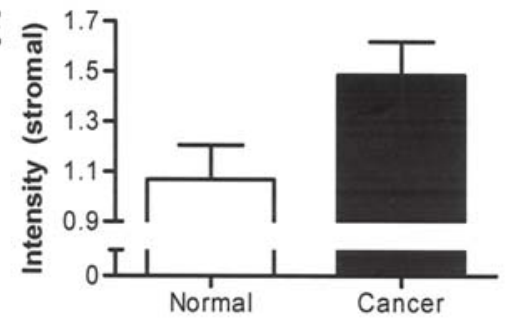

B

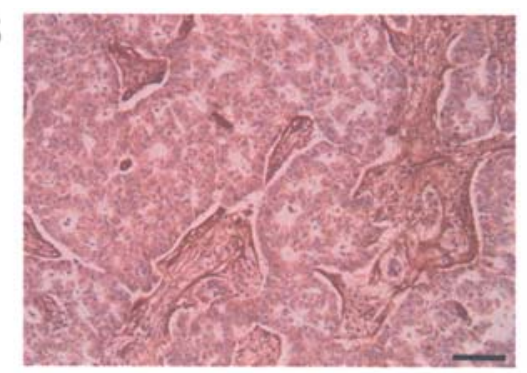

D

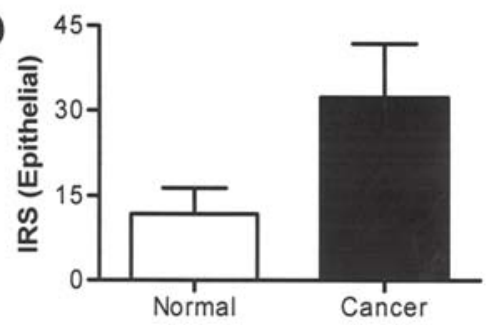

Figure 1. Expression of heparan sulphate in 32 archival breast cancer specimens and paired non-cancerous breast tissues from corresponding patients. Immunohistochemical staining of (A) normal breast tissues and (B) paired invasive ductal carcinoma samples obtained from the corresponding patients was carried out using the 10E4 antibody. A negative control section where the primary antibody was omitted is shown in (C). Statistical comparison using the Wilcoxon matched pairs test showed (D) significantly higher immunoreactivity scores (IRS) in the epithelial compartment of the carcinoma samples $(\mathrm{p}=0.0482)$, as well as (E) increased staining intensity in the stromal compartment $(\mathrm{p}=0.0067)$. Values represent mean \pm SEM. Scale bars, $100 \mu \mathrm{m}$.

supplementation of chlorate-containing culture medium with exogenous sulphate blocked the increase in cell adhesion, thus confirming that the increase was indeed due to competitive inhibition of glycosaminoglycan sulphation (Fig. 2A). To further verify that glycosaminoglycan sulphation was reduced by chlorate treatment, we extracted and measured the amount of sulphated glycosaminoglycans produced by the cancer cells using the Blyscan dye-binding assay. As shown in Fig. 2C, chlorate administration resulted in $38.4 \%$ reduction in glycosaminoglycan sulphation. A decrease in sulphation of heparan sulphate was confirmed by fluorescence immunocytochemical staining of chloratetreated cells using the 10E4 anti-heparan sulphate antibody (Fig. 2D).

Comparative effects of differentially sulphated heparan sulphate species on cancer cell adhesion. Chlorate inhibits sulphation of all glycosaminoglycans and does not act specifically on heparan sulphate. Thus, to determine if the chlorate-induced increase in cancer cell adhesion was due to a reduction in sulphation of heparan sulphate molecules, bovine kidney-derived heparan sulphate was added to MCF-7 cells grown in chlorate-containing medium. As shown in Fig. 3A, supplementation of the culture medium with adequately sulphated heparan sulphate molecules completely abolished the effect of chlorate on cell adhesion, suggesting that the sulphation status of heparan sulphate is important in regulating cancer cell adhesion. To investigate this further, we repeated the above experiment but added porcine intestinederived heparan sulphate to the chlorate-containing culture medium instead of the bovine kidney-derived species. 

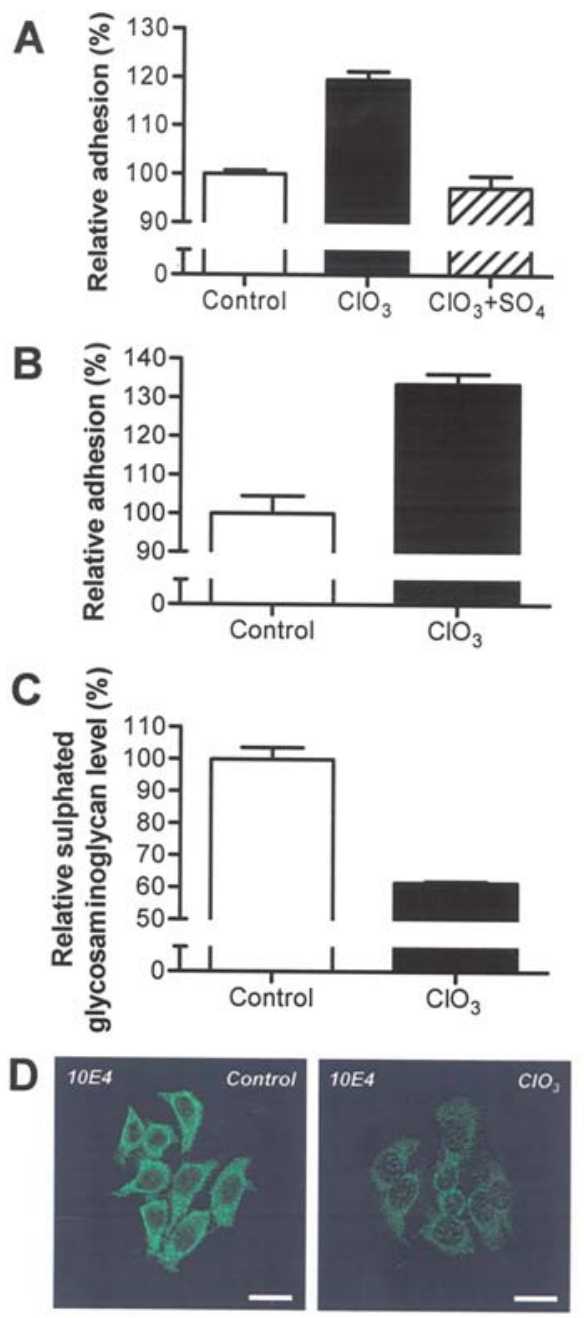

Figure 2. Effect of chlorate treatment on breast cancer cell adhesion. (A) MCF-7 cells were cultured in DMEM with $7.5 \%$ FBS in the presence of PBS (control), $30 \mathrm{mM}$ chlorate $\left(\mathrm{ClO}_{3}\right)$ or $30 \mathrm{mM}$ chlorate plus $10 \mathrm{mM}$ sulphate $\left(\mathrm{SO}_{4}\right)$. Comparison among all three groups using one-way ANOVA showed a statistically significant difference $(\mathrm{p}<0.0001)$, with the chloratealone treated group having greater cell adhesion compared to the control and the chlorate plus sulphate groups (Tukey's post test; $\mathrm{p}<0.001)$. (B) MDA-MB-231 cells cultured in chlorate-containing medium also showed an increase in cell adhesion (Student's t-test; $\mathrm{p}<0.0001$ ). (C) Chlorate treatment resulted in a significant reduction in sulphation of glycosaminoglycans produced by MCF-7 cells (Student's t-test; $\mathrm{p}=0.0005$ ). (D) Immunofluorescence staining using the 10E4 anti-heparan sulphate antibody showed reduced staining intensity of chlorate-treated $\mathrm{MCF}-7$ cells, demonstrating a decrease in sulphation of heparan sulphate molecules. Values represent mean \pm SEM of at least three replicates. Scale bars, $20 \mu \mathrm{m}$.

Heparan sulphate from porcine intestines possesses a lower degree of sulphation compared to that obtained from bovine kidney $(33,34)$. We hypothesised that it may thus be less effective in blocking the effect of chlorate on cell adhesion. Indeed, as shown in Fig. 3B, addition of porcine intestinederived heparan sulphate resulted in only a partial, instead of complete, block of the chlorate-induced increase in cell adhesion.

We also examined the effect of inhibiting glycosaminoglycan sulphation on the expression of paxillin (PAX), focal adhesion kinase (FAK) and B1-integrin (ITGB1) in chlorate-treated MCF-7 cells. Paxillin and FAK are key regulatory components in cell adhesion and cell movement (35-37). We have previously shown that $\beta 1$-integrin (ITGB1)
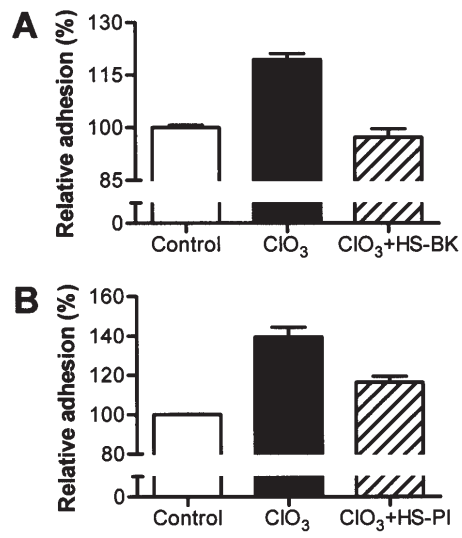

Figure 3. Sulphation status of heparan sulphate regulates breast cancer cell adhesion. MCF-7 cells were cultured in serum-containing medium supplemented with PBS (control), $30 \mathrm{mM}$ chlorate $\left(\mathrm{ClO}_{3}\right)$, (A) $30 \mathrm{mM}$ chlorate plus $100 \mathrm{ng} / \mathrm{ml}$ bovine kidney-derived heparan sulphate (HS-BK), or (B) $30 \mathrm{mM}$ chlorate plus $100 \mathrm{ng} / \mathrm{ml}$ porcine intestine-derived heparan sulphate (HS-PI). Comparison among all three groups in each panel using one-way ANOVA showed a statistically significant difference $(\mathrm{p}<0.0001)$, with an increase in cell adhesion in the group treated with chlorate alone compared against the control group (Tukey's post test; $\mathrm{p}<0.001$ ). Supplementation with HS-BK completely abolished the effect of chlorate on cell adhesion, with cells in this group possessing a similar degree of adhesion compared with those in the control group $(\mathrm{p}>0.05)$. In contrast, HS-PI was only able to partially block the effect of chlorate, and cells in this group were more adherent compared against the control group $(\mathrm{p}<0.01)$. Values represent mean \pm SEM of at least three replicates.
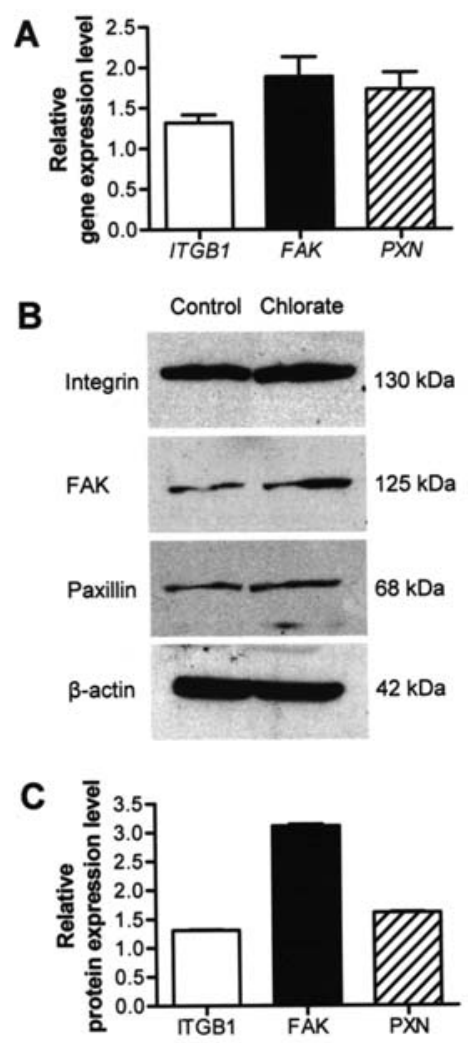

Figure 4. Effects of reduced glycosaminoglycan sulphation on ITGB1, FAK and paxillin expression. MCF-7 cells were cultured for $48 \mathrm{~h}$ in medium supplemented with PBS (control group) or $30 \mathrm{mM}$ chlorate. (A) Gene transcript levels of ITGB1, FAK and $P X N$ were measured using real-time RT-PCR. Chlorate treatment significantly upregulated the expression of $F A K(\mathrm{p}=0.0375)$ and $P X N(\mathrm{p}=0.0440)$. (B) Representative Western blot of three independent experiments. (C) Analysis by densitometry measurements showed increased levels of ITGB1 $(\mathrm{p}=0.0016)$, FAK $(\mathrm{p}=0.0002)$ and PXN $(\mathrm{p}=0.0003)$. Values represent mean \pm SEM of three replicates. 
A
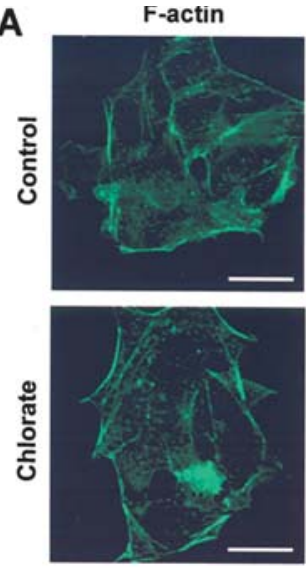

B
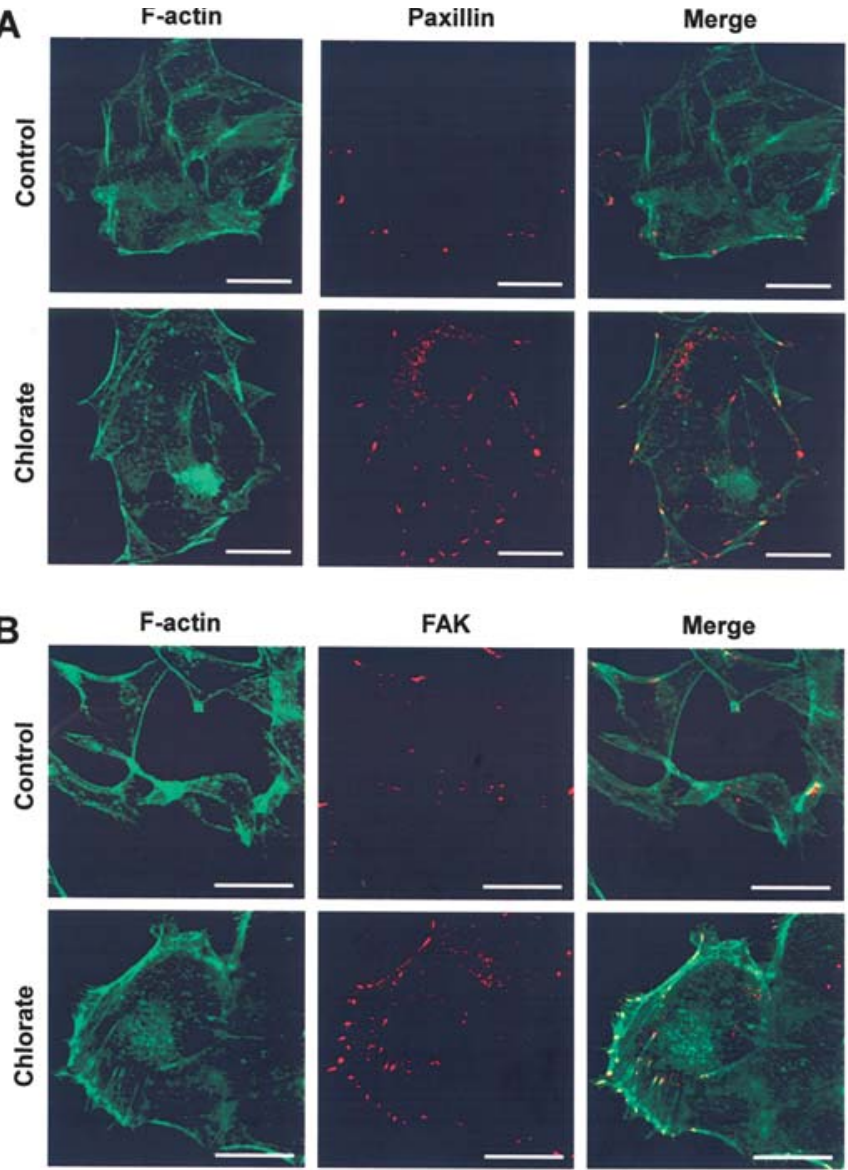

Figure 5. Fluorescence confocal microscopic analysis of focal adhesion formation. MCF-7 cells were cultured in medium supplemented with PBS (control) or $30 \mathrm{mM}$ chlorate, and immunocytochemically examined for the expression of (A) paxillin (red) or (B) FAK using the respective antibodies. Actin fibres were stained using phalloidin (green). Panels shown are representative of triplicate experiments. Scale bars, $20 \mu \mathrm{m}$.

influences the activity of FAK and paxillin, with resultant effects on breast cancer cell adhesion and spreading (23). Using real-time RT-PCR, reduction in glycosaminoglycan sulphation was shown to significantly increase the expression of $F A K$ and $P X N$ by $1.9 \mathrm{X}$ and $1.7 \mathrm{X}$ respectively (Fig. 4A). The expression of ITGBI was also upregulated, although this did not reach statistical significance. The changes in gene transcript levels were accompanied by similar upregulation in protein levels, as determined by Western blotting (Fig. 4B and C). Expressions of ITGB1, FAK and PXN proteins in chlorate-treated cells were increased by $1.3 \mathrm{X}$, $3.1 \mathrm{X}$ and $1.6 \mathrm{X}$ respectively. Using fluorescence immunocytochemistry, cells in the treatment group were found to possess an increase in focal adhesion formation together with stronger staining intensities for PXN and FAK proteins compared against those in the control group (Fig. 5).

Contrasting effects of different heparan sulphate species on cancer cell migration. To determine if the increase in cell adhesion due to reduced glycosaminoglycan sulphation would affect cancer cell migration, we cultured MCF-7 cells (Fig. 6A) and MDA-MB-231 cells (Fig. 6B) in the presence of chlorate, and measured the distance migrated by the cells across a wound gap over an 18 -h period. In both cases,
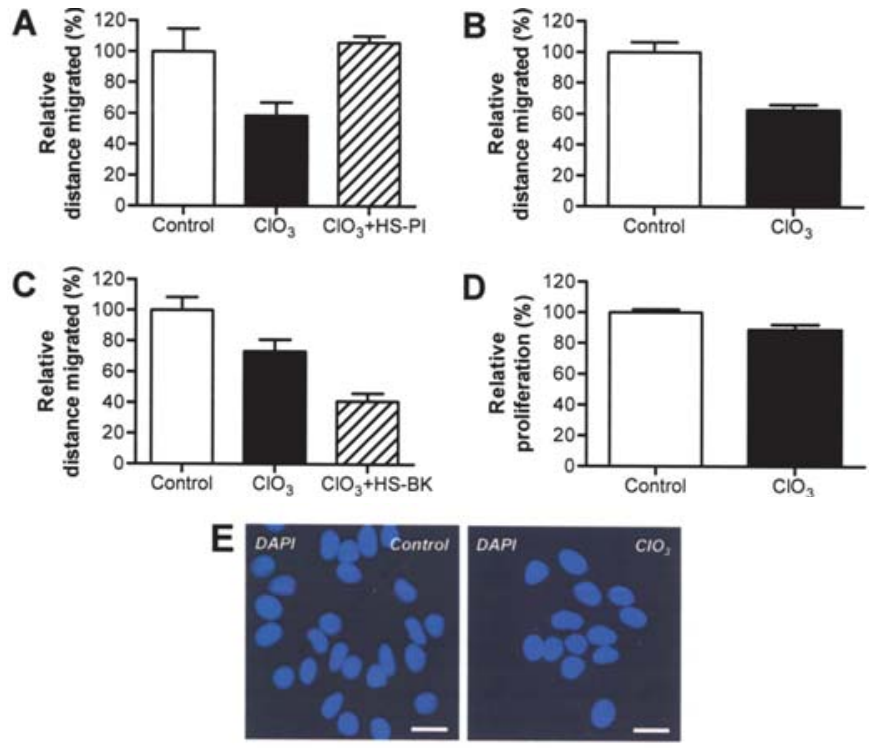

Figure 6. Effects of differentially sulphated heparan species on breast cancer cell migration. MCF-7 cells (A, C, D and E) and MDA-MB-231 cells (B) were cultured in serum-containing medium in the presence of PBS (control), $30 \mathrm{mM}$ chlorate $\left(\mathrm{ClO}_{3}\right)$, or $30 \mathrm{mM}$ chlorate plus (A) $100 \mathrm{ng} / \mathrm{ml}$ porcine intestine-derived heparan sulphate (HS-PI) or (C) bovine kidney-derived heparan sulphate (HS-BK). Comparison of cell migration among all three groups in (A) and (C) using one-way ANOVA showed a statistically significant difference $(\mathrm{p}<0.01)$, with a decrease in cell migration in the group treated with chlorate alone compared against the control group (Tukey's post test; $\mathrm{p}<0.05$ ). Supplementation of the chlorate-containing culture medium with porcine intestine-derived heparan sulphate completely blocked the effect of chlorate $(\mathrm{p}<0.05)$. In contrast, addition of bovine kidney-derived heparan sulphate resulted in a further reduction in cell migration $(\mathrm{p}<0.05)$. (B) As in the case of MCF-7 cells, inhibition of glycosaminoglycan sulphation in MDA-MB-231 cells resulted in reduced cell migration (Student's t-test; $\mathrm{p}<0.01$ ). (D) Chlorate treatment decreased cell proliferation $(\mathrm{p}<0.05)$, but did not induce cell apoptosis $(\mathrm{E})$. Values represent mean \pm SEM of at least three replicates. Scale bars, $20 \mu \mathrm{m}$.

inhibition of glycosaminoglycan sulphation resulted in a significant decrease in cell migration. This chlorate-induced reduction in cell migration could be completely ablished by supplementation of the culture medium with porcine intestine-derived heparan sulphate (Fig. 6A). However, in contrast to what was observed in the cell adhesion experiments (Fig. 3), addition of bovine kidney-derived heparan sulphate to the chlorate-containing culture medium led to a significant further decrease in cell migration instead of blocking the effect of chlorate (Fig. 6C). This suggests that differentially sulphated heparan sulphate species have diametrically opposite effects on breast cancer cell migration.

To examine if changes in cell proliferation as a result of chlorate treatment would confound the interpretation of the wound gap cell migration data, we cultured MCF-7 cells in medium supplemented with chlorate and measured the effect on cell growth. Despite treating the cells with chlorate for $72 \mathrm{~h}$, cell proliferation was reduced by only $11 \%$ (Fig. 6D). Although this was statistically significant, the small change in cell proliferation makes it unlikely to be an important confounding factor in interpreting the $42 \%$ decrease in cell migration resulting from chlorate treatment (Fig. 6A). Chlorate-treated cells did not show any chromatin condensation, suggesting that reducing glycosaminoglycan sulphation did not result in apoptosis (Fig. 6E). 


\section{Discussion}

We have investigated the use of heparan sulphate glycosaminoglycan as a biomarker of invasive breast ductal carcinoma in patient samples, and compared the effects of differentially sulphated porcine intestine- and bovine kidney-derived heparan sulphate species on cancer cell adhesion and migration. Adhesion of cancer cells to the extracellular matrix is an important determinant of local tumour invasion and distant metastasis (38-41). Changes in cell adhesion enable tumour cells to invade into surrounding tissues and spread to distant sites, contributing significantly to patient morbidity and mortality.

Studies on heparanase, an endoglucuronidase that hydrolyses heparan sulphate, suggest that degradation of heparan sulphate leads to enhanced breast cancer growth and invasion $(42,43)$. Upregulated expression of heparanase, with a consequential reduction in heparan sulphate level, has been reported in breast cancer with a larger primary tumour size and distant metastasis (44). These studies suggest that heparan sulphate glycosaminoglycan chains are involved in breast carcinogenesis and that their presence implies a poorer prognosis for patients. Indeed, in the present study, upregulated expression of the sulphated 10E4 epitope in heparan sulphate was seen in the epithelial and stromal compartments of invasive ductal carcinoma compared with the corresponding normal breast tissues.

However, recent studies have shown that not all heparan sulphate chains are bad, and that the sulphation status of different heparan sulphate species is an important determinant of the biological effects of these molecules on cancer cells. This has been highlighted in the past few years in reports on the SULF-1 gene, which codes for the enzyme sulfatase-1 that removes 6-O-sulphate groups from heparan sulphate (45-47). Loss of 6-O-sulphate groups was shown to inhibit growth of breast, pancreatic and hepatocellular cancers. In contrast, absence of $S U L F-1$ resulted in chemoresistance. Our experiments with chlorate, which competitively inhibits glycosaminoglycan sulphation and thus mimics overexpression of sulphatase-1 in the loss of 6-O-sulphate groups, showed an increase in cell adhesion and a reduction in cell proliferation. This phenomenon could be blocked by addition of adequately sulphated heparan sulphate to the culture medium, with bovine kidney-derived heparan sulphate containing a larger number of sulphate groups being more efficacious than porcine intestine-derived heparan sulphate (Fig. 3).

Interestingly, heparan sulphate regulation of breast cancer cell migration appears to be affected not only by the number of sulphate groups present but also by the position of the sulphate groups. Thus, inhibition of heparan sulphation, as well as the presence of highly sulphated bovine kidneyderived heparan sulphate, both led to a significant reduction in cell migration (Fig. 6). In contrast, optimally sulphated porcine intestine-derived heparan sulphate was able to block the effect of chlorate treatment. The results are in agreement with the recently proposed concept of a 'heparanome', in which differentially sulphated sugar sequences regulate the biological activities of different heparan sulphate species $(8,48)$.
Heparan sulphate has been shown to affect cancer cellular behaviour through several mechanisms $(9,49)$. It is able to bind to and interact with a multitude of growth factors and signalling proteins, resulting in stimulation of growth and metastasis of cancer cells (7). Heparan sulphate in the extracellular matrix also acts as a reservoir for aggregation of growth and angiogenic factors. Furthermore, binding of heparan sulphate to these molecules could protect them from degradation and thus prolong their effects on cancer cells. In breast cancer cells, fibroblast growth factor-2 (FGF-2) binds to heparan sulphate and stimulates cellular proliferation. Degradation of heparan sulphate by heparinase treatment abolished binding of the growth factor as well as the FGF-2induced tumour growth (30). Down-regulation of SULF-1 in MDA-MB-468 breast cancer cells, with the resultant persistent presence of 6-O-sulphate groups on heparan sulphate molecules, increases autocrine activation of the epidermal growth factor receptor-extracellular signalregulated kinase (EGFR-ERK) pathway, mediated via amphiregulin and heparin-binding EGF-like growth factor (HB-EGF) (50). In addition, loss of SULF-1 has been shown to increase cell proliferation in tumour-associated angiogenesis through FGF-2, hepatocyte growth factor, and vascular endothelial growth factor (VEGF) signalling.

Heparan sulphate is capable of binding to fibronectin and many other components of the extracellular matrix, and helps to regulate cell adhesion (7). Integrin-mediated cell adhesion leads to recruitment of the cytoplasmic protein tyrosine kinase FAK to focal adhesion sites, and the phosphorylation of both FAK and paxillin (36,51-55). The transmembrane heparan sulphate proteoglycan syndecan-4 is an essential element in the formation of focal adhesions (56-58). Expression of syndecan-4 in Chinese hamster ovary $(\mathrm{CHO})$ cells resulted in increased numbers of focal adhesion complexes (56). On the other hand, $\mathrm{CHO}$ cell mutants deficient in glycosaminoglycans showed reduced focal adhesion formation when cultured on a fibronectin substrate (59). In our experiments, reduction in heparan sulphation in MCF-7 breast cancer cells was shown to increase cancer cell adhesion and upregulate FAK and paxillin at both gene transcript and protein levels, and this could be completely blocked by exogenous heparan sulphate.

Heparan sulphate has been shown to be a key player in a number of signalling pathways in cell migration. It has been reported to modulate transendothelial migration of monocytes by regulating G-protein-dependent signalling (60). HT1080 fibrosarcoma cells that overexpressed the heparan sulphate proteoglycan syndecan-2 showed activation of the small GTPase Rac and increased cell migration (61). Furthermore, in addition to acting as a co-receptor in FGF signalling, heparan sulphate may act as a direct receptor in the FGF-2 activation of ERK1/2, which is required for bronchial epithelial and corneal epithelial cell migration (62-64).

In conclusion, we have shown that heparan sulphate is a useful biomarker of breast invasive ductal carcinoma, and is involved in regulating cancer cell adhesion, migration and focal adhesion complex formation through different sulphation patterns on its sugar residues. A better understanding of the effects of differentially sulphated heparan sulphate species 
on cancer cell behaviour is important for the development of these molecules into therapeutic targets for breast cancer.

\section{Acknowledgements}

The authors are grateful to Lang-Hiong Sii for technical assistance. The project was supported by Grants NMRC/ 0772/2003 and NMRC/1023/2005 from the National Medical Research Council, Singapore (G.W.Y.), and Grant MS0004 from the Singapore Cancer Syndicate (P.H.T.). C.H.G. is the recipient of a graduate research scholarship from the National University of Singapore.

\section{References}

1. Key TJ, Verkasalo PK and Banks E: Epidemiology of breast cancer. Lancet Oncol 2: 133-140, 2001.

2. Hortobagyi GN, de la Garza Salazar J, Pritchard K, et al: The global breast cancer burden: variations in epidemiology and survival. Clin Breast Cancer 6: 391-401, 2005.

3. Thor AD, Wang J and Bartow SA: The breast. In: Rubin's Pathology: Clinicopathologic Foundations of Medicine. 4th edition. Rubin E, Gorstein F, Rubin R, Schwarting R and Strayer D (eds). Lippincott Williams \& Wilkins, Philadelphia, pp996-1017, 2005

4. Rosen PP: Rosen's Breast Pathology. 2nd edition. Lippincott Williams \& Wilkins, Philadelphia, 2001.

5. Conrad HE: Heparin-binding proteins. Academic Press, San Diego, 1998.

6. Sharon N: IUPAC-IUB Joint Commission on Biochemical Nomenclature (JCBN). Nomenclature of glycoproteins, glycopeptides and peptidoglycans. Recommendations 1985. Eur J Biochem 159: 1-6, 1986.

7. Bernfield M, Gotte M, Park PW, Reizes O, Fitzgerald ML, Lincecum J and Zako M: Functions of cell surface heparan sulfate proteoglycans. Annu Rev Biochem 68: 729-777, 1999.

8. Turnbull J, Powell A and Guimond S: Heparan sulfate: decoding a dynamic multifunctional cell regulator. Trends Cell Biol 11: 75-82, 2001.

9. Yip GW, Smollich M and Gotte M: Therapeutic value of glycosaminoglycans in cancer. Mol Cancer Ther 5: 2139-2148, 2006.

10. Ringvall M, Ledin J, Holmborn K, et al: Defective heparan sulfate biosynthesis and neonatal lethality in mice lacking Ndeacetylase/N-sulfotransferase-1. J Biol Chem 275: 25926-25930, 2000.

11. Bullock SL, Fletcher JM, Beddington RS and Wilson VA: Renal agenesis in mice homozygous for a gene trap mutation in the gene encoding heparan sulfate 2-sulfotransferase. Genes Dev 12: 1894-1906, 1998.

12. Wilson VA, Gallagher JT and Merry CL: Heparan sulfate 2-Osulfotransferase (Hs2st) and mouse development. Glycoconj J 19: 347-354, 2002.

13. Barbareschi M, Maisonneuve P, Aldovini D, et al: High syndecan-1 expression in breast carcinoma is related to an aggressive phenotype and to poorer prognosis. Cancer 98: 474-483, 2003.

14. Leivonen M, Lundin J, Nordling S, von Boguslawski K and Haglund C: Prognostic value of syndecan-1 expression in breast cancer. Oncology 67: 11-18, 2004.

15. Tsanou E, Ioachim E, Briasoulis E, et al: Clinicopathological study of the expression of syndecan-1 in invasive breast carcinomas correlation with extracellular matrix components. J Exp Clin Cancer Res 23: 641-650, 2004.

16. Gotte M, Kersting C, Ruggiero M, Tio J, Tulusan AH, Kiesel L and Wulfing P: Predictive value of syndecan-1 expression for the response to neoadjuvant chemotherapy of primary breast cancer. Anticancer Res 26: 621-627, 2006.

17. Gotte M, Kersting C, Radke I, Kiesel L and Wulfing P: An expression signature of syndecan-1 (CD138), E-cadherin and c-met is associated with factors of angiogenesis and lymphangiogenesis in ductal breast carcinoma in situ. Breast Cancer Res 9: R8, 2007.

18. Matsuda K, Maruyama H, Guo F, et al: Glypican-1 is overexpressed in human breast cancer and modulates the mitogenic effects of multiple heparin-binding growth factors in breast cancer cells. Cancer Res 61: 5562-5569, 2001.
19. Koo CY, Bay BH, Lui PC, Tse GM, Tan PH and Yip GW: Immunohistochemical expression of heparan sulfate correlates with stromal cell proliferation in breast phyllodes tumors. Mod Pathol 19: 1344-1350, 2006.

20. Yip GW, Ferretti P and Copp AJ: Heparan sulphate proteoglycans and spinal neurulation in the mouse embryo. Development 129: 2109-2119, 2002.

21. Kuzuya M, Asai T, Kanda S, Maeda K, Cheng XW and Iguchi A: Glycation cross-links inhibit matrix metalloproteinase- 2 activation in vascular smooth muscle cells cultured on collagen lattice. Diabetologia 44: 433-436, 2001.

22. Lin VC, Woon CT, Aw SE and Guo C: Distinct molecular pathways mediate progesterone-induced growth inhibition and focal adhesion. Endocrinology 144: 5650-5657, 2003.

23. Lin VC, Ng EH, Aw SE, Tan MG, Ng EH and Bay BH: Progesterone induces focal adhesion in breast cancer cells MDAMB-231 transfected with progesterone receptor complementary DNA. Mol Endocrinol 14: 348-358, 2000.

24. Tuckett F and Morriss-Kay G: Alcian blue staining of glycosaminoglycans in embryonic material: effect of different fixatives. Histochem J 20: 174-182, 1988.

25. Lim D, Phan TT, Yip GW and Bay BH: Up-regulation of metallothionein isoforms in keloid keratinocytes. Int J Mol Med 17: 385-389, 2006.

26. Laborda J: 36B4 cDNA used as an estradiol-independent mRNA control is the cDNA for human acidic ribosomal phosphoprotein PO. Nucleic Acids Res 19: 3998, 1991.

27. van den Born J, Salmivirta K, Henttinen T, et al: Novel heparan sulfate structures revealed by monoclonal antibodies. J Biol Chem 280: 20516-20523, 2005.

28. David G, Bai XM, van der Schueren B, Cassiman JJ and van den Berghe H: Developmental changes in heparan sulfate expression: in situ detection with mAbs. J Cell Biol 119: 961$975,1992$.

29. Greve H, Cully Z, Blumberg P and Kresse H: Influence of chlorate on proteoglycan biosynthesis by cultured human fibroblasts. J Biol Chem 263: 12886-12892, 1988.

30. Delehedde M, Deudon E, Boilly B and Hondermarck H: Heparan sulfate proteoglycans play a dual role in regulating fibroblast growth factor-2 mitogenic activity in human breast cancer cells. Exp Cell Res 229: 398-406, 1996.

31. Safaiyan F, Lindahl U and Salmivirta M: Selective reduction of 6-O-sulfation in heparan sulfate from transformed mammary epithelial cells. Eur J Biochem 252: 576-582, 1998.

32. Safaiyan F, Kolset SO, Prydz K, Gottfridsson E, Lindahl U and Salmivirta M: Selective effects of sodium chlorate treatment on the sulfation of heparan sulfate. J Biol Chem 274: 36267-36273, 1999.

33. Wei Z, Lyon M and Gallagher JT: Distinct substrate specificities of bacterial heparinases against N-unsubstituted glucosamine residues in heparan sulfate. J Biol Chem 280: 15742-15748, 2005.

34. Toida T, Yoshida H, Toyoda $\mathrm{H}$, et al: Structural differences and the presence of unsubstituted amino groups in heparan sulphates from different tissues and species. Biochem J 322: 499-506, 1997.

35. Vicente-Manzanares M, Webb DJ and Horwitz AR: Cell migration at a glance. J Cell Sci 118: 4917-4919, 2005.

36. Turner CE: Paxillin. Int J Biochem Cell Biol 30: 955-959, 1998.

37. Turner CE: Paxillin and focal adhesion signalling. Nat Cell Biol 2: E231-E236, 2000

38. Okegawa T, Li Y, Pong RC and Hsieh JT: Cell adhesion proteins as tumor suppressors. J Urol 167: 1836-1843, 2002.

39. Pupa SM, Menard S, Forti S and Tagliabue E: New insights into the role of extracellular matrix during tumor onset and progression. J Cell Physiol 192: 259-267, 2002.

40. Boudreau $\mathrm{N}$ and Bissell MJ: Extracellular matrix signaling: integration of form and function in normal and malignant cells. Curr Opin Cell Biol 10: 640-646, 1998.

41. Liotta LA and Kohn EC: The microenvironment of the tumourhost interface. Nature 411: 375-379, 2001.

42. Vlodavsky I, Friedmann Y, Elkin M, et al: Mammalian heparanase: gene cloning, expression and function in tumor progression and metastasis. Nat Med 5: 793-802, 1999.

43. Cohen I, Pappo O, Elkin M, et al: Heparanase promotes growth, angiogenesis and survival of primary breast tumors. Int J Cancer 118: 1609-1617, 2006.

44. Maxhimer JB, Quiros RM, Stewart R, et al: Heparanase-1 expression is associated with the metastatic potential of breast cancer. Surgery 132: 326-333, 2002. 
45. Lai JP, Chien JR, Moser DR, et al: hSulf1 sulfatase promotes apoptosis of hepatocellular cancer cells by decreasing heparinbinding growth factor signaling. Gastroenterology 126: 231-248, 2004.

46. Abiatari I, Kleeff J, Li J, Felix K, Buchler MW and Friess H: Hsulf-1 regulates growth and invasion of pancreatic cancer cells. J Clin Pathol 59: 1052-1058, 2006.

47. Narita K, Staub J, Chien J, et al: HSulf-1 Inhibits angiogenesis and tumorigenesis in vivo. Cancer Res 66: 6025-6032, 2006.

48. Lamanna WC, Kalus I, Padva M, Baldwin RJ, Merry CL and Dierks T: The heparanome-the enigma of encoding and decoding heparan sulfate sulfation. J Biotechnol 129: 290-307, 2007.

49. Gotte M and Yip GW: Heparanase, hyaluronan, and CD44 in cancers: a breast carcinoma perspective. Cancer Res 66: 1023310237,2006

50. Narita K, Chien J, Mullany SA, Staub J, Qian X, Lingle WL and Shridhar V: Loss of HSulf-1 expression enhances autocrine signaling mediated by amphiregulin in breast cancer. J Biol Chem 282: 14413-14420, 2007.

51. LaFlamme SE and Auer KL: Integrin signaling. Semin Cancer Biol 7: 111-118, 1996.

52. Schaller MD: Biochemical signals and biological responses elicited by the focal adhesion kinase. Biochim Biophys Acta 1540: 1-21, 2001.

53. Liu S, Thomas SM, Woodside DG, Rose DM, Kiosses WB Pfaff $\mathrm{M}$ and Ginsberg $\mathrm{MH}$ : Binding of paxillin to alpha4 integrins modifies integrin-dependent biological responses. Nature 402: 676-681, 1999.

54. Schaller MD, Otey CA, Hildebrand JD and Parsons JT: Focal adhesion kinase and paxillin bind to peptides mimicking beta integrin cytoplasmic domains. J Cell Biol 130: 1181-1187, 1995.

55. Burridge K, Turner CE and Romer LH: Tyrosine phosphorylation of paxillin and pp125FAK accompanies cell adhesion to extracellular matrix: a role in cytoskeletal assembly. J Cell Biol 119: 893-903, 1992
56. Longley RL, Woods A, Fleetwood A, Cowling GJ, Gallagher JT and Couchman JR: Control of morphology, cytoskeleton and migration by syndecan-4. J Cell Sci 112: 3421-3431, 1999

57. Woods A and Couchman JR: Integrin modulation by lateral association. J Biol Chem 275: 24233-24236, 2000

58. Couchman JR and Woods A: Syndecan-4 and integrins: combinatorial signaling in cell adhesion. J Cell Sci 112: 3415-3420, 1999.

59. LeBaron RG, Esko JD, Woods A, Johansson S and Hook M Adhesion of glycosaminoglycan-deficient Chinese hamster ovary cell mutants to fibronectin substrata. J Cell Biol 106: 945-952, 1988.

60. Floris S, van den Born J, van der Pol SM, Dijkstra CD and de Vries HE: Heparan sulfate proteoglycans modulate monocyte migration across cerebral endothelium. J Neuropathol Exp Neurol 62: 780-790, 2003.

61. Park H, Han I, Kwon HJ and Oh ES: Focal adhesion kinase regulates syndecan-2-mediated tumorigenic activity of HT1080 fibrosarcoma cells. Cancer Res 65: 9899-9905, 2005.

62. Graness A, Chwieralski CE, Reinhold D, Thim L and Hoffmann W: Protein kinase C and ERK activation are required for TFF-peptide-stimulated bronchial epithelial cell migration and tumor necrosis factor-alpha-induced interleukin-6 (IL-6) and IL-8 secretion. J Biol Chem 277: 18440-18446, 2002.

63. Sharma GD, He J and Bazan HE: p38 and ERK1/2 coordinate cellular migration and proliferation in epithelial wound healing: evidence of cross-talk activation between MAP kinase cascades. J Biol Chem 278: 21989-21997, 2003.

64. Chua CC, Rahimi N, Forsten-Williams K and Nugent MA: Heparan sulfate proteoglycans function as receptors for fibroblast growth factor-2 activation of extracellular signal-regulated kinases 1 and 2. Circ Res 94: 316-323, 2004. 